\title{
Heart Rate Variability and Cocaine: a Systematic Review of Human Studies
}

\author{
Julian Koenig ${ }^{1, *}$; Barbara Menke ${ }^{2}$; Thomas K. Hillecke ${ }^{2}$; Julian F Thayer ${ }^{1}$; Marc N Jarczok $^{3}$ \\ ${ }^{1}$ Department of Psychology, The Ohio State University, Columbus, OH, USA \\ ${ }^{2}$ School of Therapeutic Sciences, SRH University of Applied Sciences, Heidelberg, Germany \\ ${ }^{3}$ Mannheim Institute of Public Health, Social and Preventive Medicine, Heidelberg University, Mannheim, Germany \\ ${ }^{*}$ Corresponding author: Julian Koenig, Department of Psychology, The Ohio State University, 175 Psychology Building, 1835 Neil Avenue, Columbus, OH 43210, USA. Tel: +49-6213839918, \\ Fax:+49-6213839920, E-mail: koenig.393@osu.edu
}

Received: March 9, 2014; Revised: March 20, 2014; Accepted: March 25, 2014

\begin{abstract}
Cocaine affects the autonomic nervous system (ANS). Cardiovascular effects of cocaine have been extensively studied by measures of mean heart rate (HR) or blood pressure (BP). The present systematic review aims to summarize the current evidence on the effects of cocaine on heart rate variability (HRV) in human subjects.

A systematic search of electronic databases (PUBMED, PSYNDEX and EMBASE) based on the "Preferred Reporting Items for Systematic Reviews and Meta-Analyses (PRISMA)" statement was employed. Studies were screened for eligibility based on pre-specified inclusion criteria. The search revealed a total of 48 papers after removing duplicates. Eleven studies fitting the inclusion criteria were included in the systematic review. Evidence on the effects of cocaine on HRV is rare. Existing studies either address the impact of acute cocaine administration in adults or the effect of prenatal cocaine exposure on infants in various age groups. However, HRV is a promising index to study ANS function within this particular field of research. Several suggestions for future research are provided.
\end{abstract}

Keywords:Heart Rate Variability; Cocaine; Humans

\section{Context}

Cocaine affects the autonomic nervous system (ANS). Cardiovascular effects of cocaine have been extensively studied. The major pharmacological property of cocaine that affects the cardiovascular system is its impact on catecholamines (i.e. dopamine and norepinephrine). It blocks the reuptake of catecholamines at the presynaptic level in the central and peripheral nervous systems and increases the release of such substances from both central and peripheral stores, resulting in increased levels of norepinephrine in the vascular smooth muscle, stimulating postsynaptic alpha-receptors, with a subsequent increase in calcium flux and a vasoconstrictor response (1-3). Furthermore, cocaine has a local anesthetic effect on the heart, by blocking the fast sodium channels in the myocardium, resulting in a depression of depolarization and a slowing of conduction velocity (1).

While the effect of cocaine on the cardiovascular system (4) has been extensively studied using measures of blood pressure (BP, e.g. (5)), heart rate (HR, e.g.(1)) or likewise parameters of cardiovascular activity under different conditions, studies on the effect of cocaine on heart rate variability (HRV) are rare. The heart rate variability (HRV) represents the continuous interplay between the sympathetic and parasympathetic branches of the ANS in regulating the HR. In this comprehensive review, we attempt to summarize current findings on the influence of cocaine on time and frequency domain measures of HRV.

\section{Evidence Acquisition}

\subsection{Search Strategy}

This review uses a systematic approach, according to the "Preferred Reporting Items for Systematic Reviews and Meta-Analyses (PRISMA)" statement (6), to extract research studies on the relationships between HRV and acute cocaine intake. The following computerized databases were searched from 1st of January 1996 up to the 31st December 2012: PUBMED (MEDLINE), PSYNDEX and EMBASE. The search was restricted to publications published within this time frame, since the first guideline on standards of measurements, physiological interpretation and clinical use of HRV was published in 1996 (7). Articles were considered for inclusion if they had a focus on cocaine (search term keyword: "cocaine") and (AND) measured HRV (search term keyword: "heart rate variability"

Implication for health policy/practice/research/medical education:

The current review summarizes all existing studies on the effect of cocaine on heart rate variability (HRV) in humans, providing researchers with an updated perspective on this topic. While evidence on the effects of cocaine on HRV is rare, this review encourages the use of HRV as an index of autonomic nervous system function as a research tool.

Copyright (C) 2014, Tehran University of Medical Sciences; Published by Kowsar Corp. This is an open-access article distributed under the terms of the Creative Commons Attribution License, which permits unrestricted use, distribution, and reproduction in any medium, provided the original work is properly cited. 


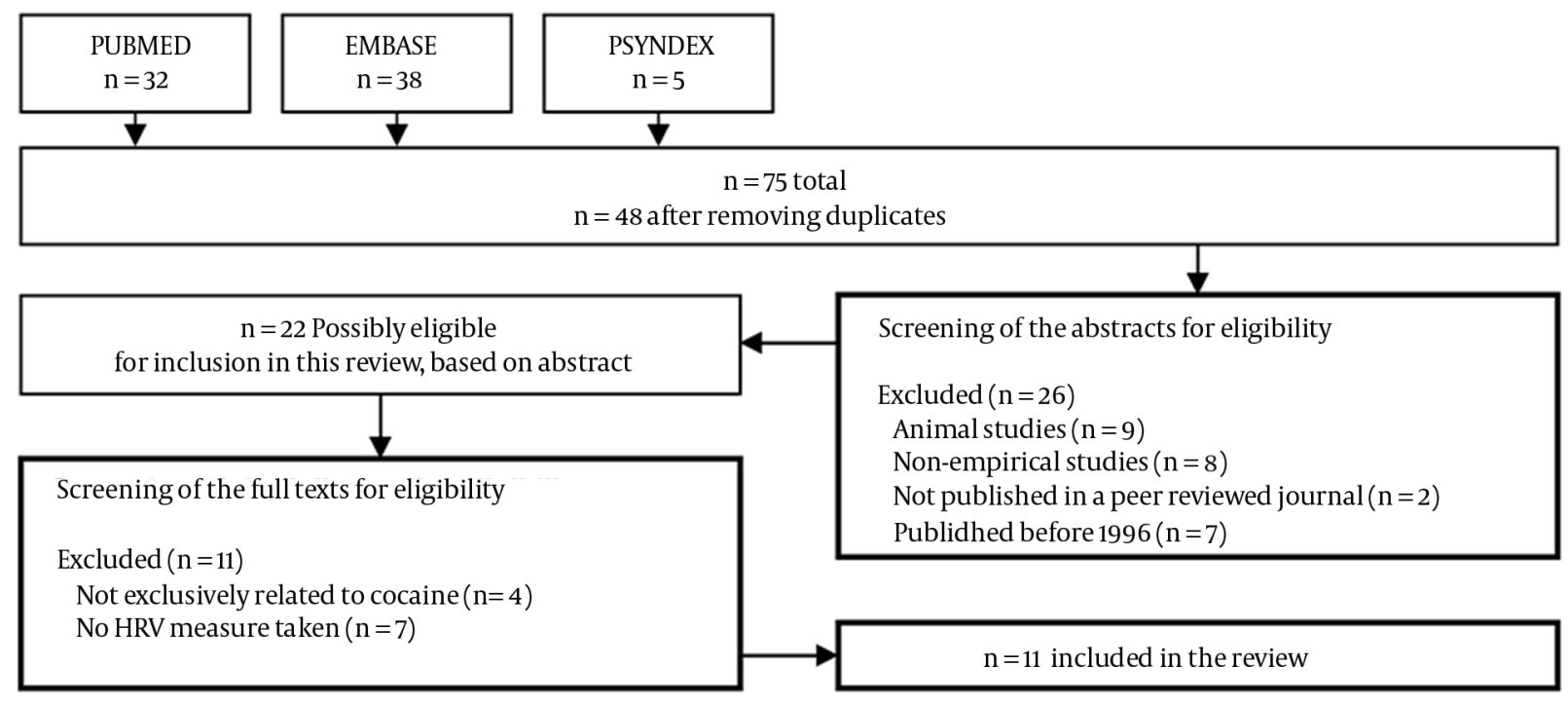

Figure 1. Figure 1. Search Flow Diagram

OR "HRV"). Details were recorded regarding the number of studies found in the databases using the search terms as depicted within the flow-chart (Figure 1).

The abstracts of the manuscripts were then screened for eligibility independently by two authors (JKand MNJ). Differences in initial study identification and selection for review were compared and deviations were discussed until a consensus on the disposition of each under the study could be reached. The screening was based on the following criteria: (a) empirical investigation with HRV measures obtained in human subjects; (b) specifically cocaine related (i.e. reported acute cocaine intake as independent variable or long-term impact of cocaine); (c) published in a peer-reviewed journal; and (d) published in English. Included papers were reviewed in full text for information on (1) study design and subjects, (2) details on cocaine use (i.e. dose, method to determine long-term cocaine intake) (3) method of HRV measurement, and (4) data on HRV time-and (5) frequency-domain measures. The few differences in the evaluation were addressed, reaching a consensus presented in Figure 1. The number of studies meeting the pre-specified inclusion criteria, number of studies excluded, and reasons for exclusion were recorded.

\subsection{Data Extraction}

Study information on author, country, study population, sample size, gender ratio, age of participants, study design, and main study focus, were extracted from the papers retrieved in full-text. Furthermore, details regarding the method of cocaine intake, the cocaine dose, the method of HRV recording, available data length for analysis and HRV measures obtained from data sets were ex- tracted and summarized within a comprehensive table. Findings and strength of reported effects were derived from the papers retrieved in full-text.

\section{Results}

The search in the selected databases revealed a total of 48 articles after removing the duplicates (Figure 1). With a total of 38 hits, EMBASE revealed the most findings when compared to PUBMED $(n=32)$ and PSYNDEX $(n=5)$. A total of 48 articles were considered for inclusion in the review after removing duplicates. The abstract of all studies was retrieved for further screening of eligibility. Nine animal studies and eight non-investigational articles (e.g. reviews, comments) were excluded. Furthermore, two papers not published in a peer reviewed journal and seven papers published before 1996 were excluded, based on the specified criteria, leaving 22 articles for further consideration, which were retrieved in full-text. Four papers were excluded because they did not specifically relate to cocaine (i.e. alcohol, cocaine and other drugs). Another seven papers were excluded which were not reporting HRV (i.e. only mean HR); leaving a total of 11 studies included in the systematic review.

\subsection{Nature of the Included Studies}

Three studies reported results from experimental designs addressing the cardiovascular effects of acute cocaine intake either in healthy volunteers (8), non-treatment-seeking cocaine-experienced volunteers (9), or cocaine dependent men (10). The majority of studies investigated HRV in clinical studies, in particular in prenatal cocaine exposed (PCE) infants (11-18). Table 1 provides an overview of the included studies and the main study focus. 
KoenigJ et al.

\begin{tabular}{|c|c|c|c|c|c|}
\hline $\begin{array}{l}\text { Authors, }(\mathrm{y}) \\
\text { [ref] }\end{array}$ & Country & Population & $\begin{array}{c}\text { Cocaine Dose/ } \\
\text { Application }\end{array}$ & HRV Measures Taken & Main Study Focus \\
\hline $\begin{array}{l}\text { Garde et al. } \\
\text { (2011)(15) }\end{array}$ & USA & $\begin{array}{c}\text { Infants, PCE }(\mathrm{n}=9) \\
\text { controls }(\mathrm{n}=12)\end{array}$ & $\begin{array}{l}\text { PCE by maternal self- } \\
\text { report or neonatal } \\
\text { toxicological urinalysis }\end{array}$ & $\begin{array}{c}\text { SDRR, LF (0.03 and } 0.1 \\
\text { Hz), MF (0.1 and } 0.2 \\
\mathrm{~Hz} \text { ), HF (0.3 and } 2 \mathrm{~Hz} \text { ), } \\
\text { LF/HF (here: } \mathrm{LF}+\mathrm{MF} / \\
\text { HF) }\end{array}$ & $\begin{array}{l}\text { Effects of prenatal cocaine } \\
\text { exposure on the dynamics } \\
\text { of heart rate variability in full- } \\
\text { term neonates during sleep }\end{array}$ \\
\hline
\end{tabular}

\begin{tabular}{|c|c|c|c|c|c|c|}
\hline $\begin{array}{l}\text { Haigney et } \\
\text { al. (2006)(9) }\end{array}$ & USA & $\begin{array}{l}\text { Non-treatment- } \\
\text { seeking cocaine- } \\
\text { experienced } \\
\text { volunteers }(n=29)\end{array}$ & $\begin{array}{l}20 \mathrm{mg} \text { and } 40 \mathrm{mg} \text { IV } \\
\text { infusions of Cocaine on } \\
\text { successive days }\end{array}$ & HRv, QTm, QTv, QTVI & $\begin{array}{l}\text { Effect of intravenous cocaine } \\
\text { on QT variability }\end{array}$ & $\begin{array}{l}\text { Dose-dependent } \\
\text { increase in QT } \\
\text { variability, effect } \\
\text { disappeared by } \\
45 \text { minutes after } \\
\text { the infusion, HRv } \\
\text { decreased significantly } \\
\text { at } 10 \text { minutes post } \\
\text { infusion only }\end{array}$ \\
\hline $\begin{array}{l}\text { Irwin et al. } \\
(2007)(10)\end{array}$ & USA & $\begin{array}{l}\text { Cocaine dependent } \\
\text { men }(\mathrm{n}=19) ; \\
\text { controls }(\mathrm{n}=19)\end{array}$ & $\begin{array}{l}\text { Cocaine }(40 \mathrm{mg}) \\
\text { infused over } 60 \mathrm{~s} \text { by an } \\
\text { indwelling catheter }\end{array}$ & LF, HF, LF/HF & $\begin{array}{l}\text { Effect of cocaine versus } \\
\text { placebo on monocyte } \\
\text { expression of TNF- } \alpha \text { and IL-6, } \\
\text { differences between cocaine- } \\
\text { dependent men versus } \\
\text { control subjects; potential } \\
\text { mechanism for decreases } \\
\text { of resting and stimulated } \\
\text { monocyte expression of } \\
\text { TNF- } \alpha \text { and IL- } 6 \text { in cocaine } \\
\text { dependence by assessing } \\
\text { variations in SNS and PNS }\end{array}$ & $\begin{array}{l}\text { LF/HF and HF in } \\
\text { cocaine-dependent } \\
\text { volunteers }\end{array}$ \\
\hline $\begin{array}{l}\text { John et al. } \\
(2007)(14)\end{array}$ & USA & $\begin{array}{l}\text { Near-and full-term } \\
\text { neonates PCE }(n= \\
21) ; \text { controls }(n=23)\end{array}$ & $\begin{array}{c}\text { PCE determined by } \\
\text { maternal self-report or } \\
\text { neonatal urine toxicol- } \\
\text { ogy }\end{array}$ & $\begin{array}{c}\text { SDRR, SDDRR, } \\
\text { CorSDRR, HF, LF, total } \\
\text { power, LF/total, HF/ } \\
\text { total, LF/HF }\end{array}$ & $\begin{array}{l}\text { Effects of prenatal cocaine } \\
\text { exposure on HR and HRV in } \\
\text { the presence of orthostatic } \\
\text { stress among near-and full- } \\
\text { term neonates }\end{array}$ & $\begin{array}{l}\text { SDDRR in PCE in the } \\
\text { pre-tilt and intratilt } \\
\text { segments compared } \\
\text { with controls, different } \\
\text { SDDRR peak }\end{array}$ \\
\hline $\begin{array}{l}\text { Mehta et al. } \\
(2002)(12)\end{array}$ & USA & $\begin{array}{l}2 \text { to } 6 \text { month-old } \\
\text { infants; } \mathrm{PCE}(\mathrm{n}= \\
\text { 71); other drugs (n } \\
=89) ; \text { no drugs ( } \mathrm{n} \\
\quad=77)\end{array}$ & $\begin{array}{l}\text { Exposed to cocaine } \\
\text { in-utero }\end{array}$ & $\begin{array}{l}\text { Mean N-N interval, } \\
\text { SNN-50, SDNN, } \\
\text { SDANN, SDNNi, } \\
\text { RMSSD, HF, LF, VLF, } \\
\text { ULF, total power }\end{array}$ & $\begin{array}{l}\text { HRV alternations after } \\
\text { intrauterine cocaine exposure } \\
\text { in older infants (transient or } \\
\text { persist); teratogenic effect of } \\
\text { cocaine }\end{array}$ & $\begin{array}{l}\text { at birth: SDNN, HF, } \\
\text { SNN-50, RMSSD in PCE } \\
\text { compared to controls; } \\
2 \text { to } 6 \text { months of age: } \\
\text { SNN-50, RMSSD, total } \\
\text { power in PCE compared } \\
\text { to controls }\end{array}$ \\
\hline $\begin{array}{l}\text { Mehta et al. } \\
(2002)(13)\end{array}$ & USA & $\begin{array}{l}24 \text { to } 72 \text { hour-old } \\
\text { infants, } P C E(n=97) \text {; } \\
\text { other drugs }(n=111) \text {; } \\
\text { no drugs }(n=102)\end{array}$ & $\begin{array}{l}\text { Exposed to cocaine } \\
\text { in-utero based on either } \\
\text { maternal self-report or } \\
\text { toxicology studies }\end{array}$ & $\mathrm{HRVi}$ & $\begin{array}{l}\text { Feasibility of using HRVi } \\
\text { for clinical applications by } \\
\text { assessing its reproducibility } \\
\text { and evaluating it in a cohort } \\
\text { of infants with in utero } \\
\text { cocaine exposure }\end{array}$ & $\begin{array}{l}\text { HRVi in PCE compared } \\
\text { to other or no drugs, } \\
\text { differences according } \\
\text { to degree of cocaine } \\
\text { exposure }\end{array}$ \\
\hline $\begin{array}{l}\text { Mehta et al. } \\
(2001)(11)\end{array}$ & USA & $\begin{array}{l}217 \text { infants; PCE ( } \mathrm{n} \\
=68) ; \text { other drugs } \\
(\mathrm{n}=77) ; \text { no drugs } \\
(\mathrm{n}=72)\end{array}$ & $\begin{array}{l}\text { Intrauterine cocaine } \\
\text { exposure determined } \\
\text { by maternal urine } \\
\text { and infant urine and } \\
\text { meconium testing for } \\
\text { cocaine }\end{array}$ & $\begin{array}{l}\text { RMSSD, SDNN, HF, LF, } \\
\text { total power }\end{array}$ & $\begin{array}{l}\text { Autonomic control of the } \\
\text { heart in cocaine-exposed } \\
\text { infants }\end{array}$ & $\begin{array}{l}\text { SDNN in PCE compared } \\
\text { to other or no drugs, } \\
\text { HF, LF, total power } \\
\text { compared to other } \\
\text { drugs, differences } \\
\text { according to degree of } \\
\text { cocaine exposure }\end{array}$ \\
\hline $\begin{array}{l}\text { Regalado et } \\
\text { al. (1996)(16) }\end{array}$ & USA & $\begin{array}{l}\text { Infants } 2 \text { weeks of } \\
\text { age; PCE }(n=17) ; \\
\text { controls }(n=14)\end{array}$ & $\begin{array}{l}\text { PCE determined by } \\
\text { maternal self-report } \\
\text { or neonatal urine } \\
\text { toxicology }\end{array}$ & $\begin{array}{l}\text { Interquartile range of } \\
\text { the R-R intervals }\end{array}$ & $\begin{array}{l}\text { Effect of sleep state on } \\
\text { cardiorespiratory control in } \\
\text { cocaine-exposed infants }\end{array}$ & $\begin{array}{l}\text { Interquartile range } \\
\text { of the R-R intervals } \\
\text { in QS and REM in PCE } \\
\text { compared to controls }\end{array}$ \\
\hline $\begin{array}{l}\text { Regalado et } \\
\text { al. (1998)(17) }\end{array}$ & USA & $\begin{array}{l}\text { Full-term infants, } \\
\text { PCE }(\mathrm{n}=11) \text {, controls } \\
(\mathrm{n}=11)\end{array}$ & $\begin{array}{l}\text { PCE by maternal self- } \\
\text { report or neonatal } \\
\text { toxicological urinalysis }\end{array}$ & $\begin{array}{c}\mathrm{HF}(0.3 \text { to } 2 \mathrm{~Hz}), \mathrm{MF} \\
\text { (0.1 to } 0.2 \mathrm{~Hz}), \mathrm{LF}(0.03 \\
\text { to } 0.1 \mathrm{~Hz}) \text {, total power } \\
(0 \text { to } 8 \mathrm{~Hz})\end{array}$ & $\begin{array}{l}\text { Determine what types of } \\
\text { heart rate variation account } \\
\text { for the increased heart rate } \\
\text { variability in neonates with } \\
\text { chronic cocaine exposure in } \\
\text { utero }\end{array}$ & $\begin{array}{l}\text { Total power in QS and } \\
\text { AS in PCE compared } \\
\text { to controls; MF, LF in } \\
\text { QS in PCE compared } \\
\text { to controls; LF in AS } \\
\text { in PCE compared to } \\
\text { controls }\end{array}$ \\
\hline
\end{tabular}


Koenig J et al.

\begin{tabular}{|c|c|c|c|c|c|c|}
\hline $\begin{array}{l}\text { Regalado et } \\
\text { al.(2001)(18) }\end{array}$ & USA & $\begin{array}{l}\text { Full-term neonates, } \\
2 \text { weeks of age, PCE } \\
\begin{array}{l}(\mathrm{n}=15) \text {, controls } \\
(\mathrm{n}=13)\end{array}\end{array}$ & $\begin{array}{l}\text { PCE by maternal self- } \\
\text { report or neonatal } \\
\text { toxicological urinalysis }\end{array}$ & $\begin{array}{c}\mathrm{HF}(0.3 \text { to } 2 \mathrm{~Hz}), \mathrm{MF} \\
\text { (0.1 to } 0.2 \mathrm{~Hz}), \mathrm{LF}(0.03 \\
\text { to } 0.1 \mathrm{~Hz}), \mathrm{LF} / \mathrm{HF} \text { (here: } \\
\mathrm{LF}+\mathrm{MF} / \mathrm{HF}), \text { total } \\
\text { power }\end{array}$ & $\begin{array}{l}\text { Autonomic control of heart } \\
\text { rate and respiration during } \\
\text { the neonatal period in hu- } \\
\text { man infants with prenatal } \\
\text { exposure to cocaine }\end{array}$ & $\begin{array}{l}\text { MF, LF, total power in } \\
\text { QS and AS in PCE com- } \\
\text { pared to controls; HF } \\
\text { in QS in PCE compared } \\
\text { to controls }\end{array}$ \\
\hline $\begin{array}{l}\text { Vongpa- } \\
\text { tanasin et } \\
\text { al. }(2004)(8)\end{array}$ & USA & $\begin{array}{l}\text { Healthy volunteer } \\
\text { subjects ( } \mathrm{n}=24,12 \\
\text { menand } 12 \text { women; } \\
24 \text { to } 44 \text { years of } \\
\text { age) }\end{array}$ & $\begin{array}{c}\text { Intranasal } \\
\text { administration of } \\
\text { cocaine }(2 \mathrm{mg} / \mathrm{kg})\end{array}$ & $\begin{array}{l}\text { SDNN, RMSSD, } \\
\text { pNN50, HF }\end{array}$ & $\begin{array}{l}\text { Effects of Cocaine on Heart } \\
\text { Rate Variability in Healthy } \\
\text { Subjects }\end{array}$ & $\begin{array}{l}\text { HF, SDNN, RMSSD, } \\
\text { pNN50 afterCocaine } \\
\text { administration }\end{array}$ \\
\hline
\end{tabular}

a Abbrevitions: AS, active sleep; BP, blood pressure; BRS,baroreflex sensitivity; DM CocE, double mutant Cocaine esterase; ECG, electrocardiography; HR, heart rate; HRV, heart rate variability; HRVi, HRV triangular index; HRv, mean heart rate variance; IV, intravenously; PCE, Prenatal Cocaine exposure; PNS, parasympathetic nervous system; QT interval, a time between the start of the Q wave and the end of the T wave; QTm, QT interval mean; QTv, QT interval variance; QTVI, normalized QT variability index; QS, quiet sleep; SNS, sympathetic nervous system

\begin{tabular}{|c|c|c|c|}
\hline Name & Description & Unit & ANS Branch \\
\hline HR & Simple heart rate in beats per minute & BPM & \\
\hline IBI & Raw time of R-wave to R-wave intervals in milliseconds time & $\mathrm{ms}$ & Mixed \\
\hline \multicolumn{4}{|c|}{$\begin{array}{c}\text { Time Domain Measures: Based on the Interbeat Intervals Directly or on Differences Between Successive Interbeat Intervals. In Addition, } \\
\text { There Are Both Short-Term and Long-Term Indices. }\end{array}$} \\
\hline NN & Normal-to-normal intervals & $\mathrm{ms}$ & Mixed \\
\hline SDNN & Standard deviation of all N-N intervals & $\mathrm{ms}$ & Mixed \\
\hline SDANN & $\begin{array}{c}\text { Standard deviation of the average of N-N intervals for each 5-minute period over } 24 \\
\text { hours }\end{array}$ & $\mathrm{ms}$ & Mixed \\
\hline pNN50 & Percentage of adjacent cycles that are greater than 50 ms apart & $\%$ & primalyvagally mediated \\
\hline RMSSD & $\begin{array}{l}\text { Root Mean Square of Successive Differences, in milliseconds. This index acts like a high } \\
\text { pass filter, thus removing long-term trends and slower-frequency variability from } \\
\text { the signal. Because of the frequency characteristics of the autonomic influences on } \\
\text { the heart such that vagal influences cover the full frequency range and sym-pathetic } \\
\text { influences are primarily restricted to the lower frequencies, RMSSD reflects primarily } \\
\text { vagal influences. }\end{array}$ & $\mathrm{ms}$ & Primarily vagally mediated \\
\hline
\end{tabular}

Frequency Domain Measures: Frequency Domain Analysis Yields Information About the Amount of Variance or Power in the Heart Rate or Heart Period Time Series Explained by Periodic Oscillations at Various Frequencies. Power Spectral Analysis of the Time Series Provides Basic Information on the Amount of Variance or Power as a Function of Frequency (Task Force, 1996).

\begin{tabular}{|c|c|c|c|}
\hline HF & High Frequency $(0.15-0.4 \mathrm{~Hz})$ & $\mathrm{ms}^{2}$ & primalyvagally mediated \\
\hline $\mathbf{L F}$ & Low Frequency $(0.04-0.15 \mathrm{~Hz})$ & $\mathrm{ms}^{2}$ & baroreflex activity \\
\hline VLF & Very low frequency $(0.003-0.04 \mathrm{~Hz})$ & $\mathrm{ms}^{2}$ & Mixed \\
\hline ULF & Ultra-low frequency $(<0.003 \mathrm{~Hz})$ & $\mathrm{ms}^{2}$ & Mixed \\
\hline TP & $\begin{array}{l}\text { Total power represent the variance of the measured signal around its mean value } \\
\text { exactly equal to the time domain variance of the HR time series }\end{array}$ & $\mathrm{ms}^{2}$ & Mixed \\
\hline normalization & The so-called normalized scores represent the relative value of each power component & - & Mixed \\
\hline
\end{tabular}
proportional to the total power. In addition, the VLF or DC component is often subtracted from the total power in calculating the normalized values. The DC component is defined as the spectral components with a frequency less than $0.03 \mathrm{~Hz}$. The LF-to-HF ratio (LF/HF) has been proposed to reflect the sympathovagal balance (also see below)

LF/HF LF-to-HF ratio may provide some insight into the relative relations between autonomic inputs.

\subsection{Measures}

In addition to the basic measures of the HR, such as beats per minute (BPM), variations in the HR can be evaluated by numerous methods and measures derived. These measures of HRV can be divided into two classes: the time-domain and frequency-domain mea- sures of HRV. The most commonly used measures of HRV are summarized in Table 2.

\subsection{Time Domains}

Time-domain measures can be derived from direct measurements of the normal-to-normal intervals ( $\mathrm{NN}$ in- 
KoenigJ et al.

tervals) or instantaneous HR, or from the differences between NN intervals. Within the included studies, reported time-domain measures include the mean NN interval in milliseconds (ms) (12), the mean standard deviation (SD) of all NN intervals (SDRR or SDNN in ms, $(8,11,12,14$, 15 ), the square root of the mean of the sum of the squares of differences between adjacent NN intervals (RMSSD in $\mathrm{ms},(8,11,12)$, the mean of the SDNN of all NN intervals (SDNN index or SDNNi in ms (12)), or the number of pairs of adjacent $\mathrm{NN}$ intervals differing by more than $50 \mathrm{~ms}$ divided by the total number of all NN intervals (pNN50 in \%, (8), or SNN-50 (12)). Besides these frequently used, authors reported the corrected SDRR(corSDRR, SDRR corrected for HR as described in (14), and SD of differences between successive R-R intervals (SDDRR [14]), the SD of the average of valid N-N intervals (SDANN, (12)), or the inter-quartile range of the R-R intervals (16).

\subsection{Frequency Domains}

Parametric and nonparametric methods to analysis the power spectral density (PSD) of HRV, allow the calculation of different spectral components of short and long term recordings of HRV. From short-term recordings, three different main spectral components are distinguished: very low frequency (VLF $\leq 0.04 \mathrm{~Hz}$ ), low frequency (LF, usually 0.04-0.15 Hz), and high frequency (HF, usually $0.15-0.4 \mathrm{~Hz}$ ) components. Furthermore, an ultralow frequency component (ULF) can be derived from the spectral analysis in long-term recordings (e.g. 24 hours). Depending on the length of the recording different frequency-domain measures with different frequency bands (see Table 1) are reported within the included studies including the power in $\operatorname{HF}(8,10-12,14,17,18)$; the power in $\operatorname{LF}(10-12,14,15,17,18)$; the power in ULF $(12)$, or total power $(11,12,14,17,18)$. Besides these, several studies include a mid-frequency-band (MF $[15,17,18]$ ) or a very-low-frequency band (VLF) besides the ULF (12). Traditionally, the ratio between LF and HF (LF/HF ratio) serves as another measure of HRV and was used frequently by the included studies $(10,14,15)$. Furthermore, several studies report other ratios, such as the LF+MF/HF $[15,18]$ the LF/total or HF/total $(14)$. Besides these frequently used, one study reports the mean heart rate (HRm) and variance (HRv), and QT interval mean (QTm) and variance (QTv), and a normalized QT variability index (QTVI), as described elsewhere (9). Furthermore, a single study reports the geometric triangular index (HRVi), which is the total number of all $\mathrm{N}-\mathrm{N}$ intervals divided by the height of the histogram of all N-N intervals measured on a discrete scale with bins of $7.8125 \mathrm{~ms}$, and with no adjustment for recording length (13).

\subsection{Experimental Studies}

Three experimental studies investigated the impact of cocaine administration on HRV. While one study included non-treatment-seeking cocaine-experienced volunteers (9), another included cocaine dependent men (10), and another administered cocaine to healthy volunteer subjects (8). The studies also differed by the dose of cocaine administered (Table 1$)$. The study by Haigney et al. (9) revealed a dose-dependent increase in QT variability, which disappeared by 45 minutes after the infusion. The authors found that the mean heart rate variance (HRv) decreased significantly at 10 minutes post cocaine infusion, indicating a depression in normalized HRV. The authors argue that cocaine reduces vagal activity, thereby reducing variability of the $\mathrm{HR}$, which can potentiate cocaine's sympathomimetic effects. As these effects were manifest by 10 minutes but were not temporally disconnected from the peal increase in QT variance, the authors suggest that modulation of autonomic tone accounts only for a part of cocaine's proarrhythmic effects (9).

Irwin et al. (10) found, that compared with control subjects, cocaine-dependent volunteers had higher levels of the ratio of LF/HF power, along with decreases in the HF power. The authors conclude that these findings indicate a shift toward sympathetic dominance and a withdrawal of parasympathetic activity at rest in cocaine-dependent volunteers compared with healthy control subjects. The study by Vongpatanasin et al. (8) administered intranasal cocaine to healthy volunteers to study effects on HRV. The authors found a significant decrease of HF, SDNN, RMSSD, and pNN50 after Cocaine administration. The authors revealed a striking similarity in the time course of the observed increase in HR and decrease in HF power. The authors state, that they found cocaine causes an unequivocal decrease in HF power, implicating an important vagolytic component to this positive chronotropic response (increase in HR). They suggest a major vagolytic action of cocaine on the human sinus node.

\subsection{Clinical Studies}

The majority of the included studies had a clinical nature, with all of them investigating the effects of prenatal cocaine exposure (PCE) on the dynamics of HRV. While one study focused on general HRV difference in neonates with PCE versus controls (11), four studies focused on HRV in PCE neonates during sleep (15-18), one study addressed HRV in PCE near and full-term neonates in the presence of orthostatic stress (14), one studied HRV in two to six month-old infants with PCE (12), and one study assessed the feasibility of a particular HRV measure (HRVi) for clinical applications by assessing its reproducibility in a cohort of infants with in-utero cocaine exposure (13).

The study by Mehta et al. (11) found decreased SDNN, HF, LF, and total power in 24 hour recordings of HRV of PCE neonates compared to neonates exposed to other drugs or none. Furthermore, the authors found differences according to the degree of cocaine exposure. Within a later study by the same authors (13), a decreased HRVi in PCE neonates compared to neonates exposed to other or no drugs was found. Again differences according to the degree of cocaine exposure were found. A third study by 
these authors (12) investigated HRV alterations after intrauterine cocaine exposure in older infants. In near and full term PCE neonates at birth, they found decreased SDNN, HF, SNN-50, and RMSSD compared to controls. Interestingly, they found increased SNN-50, RMSSD, and total power in PCE infants compared to controls at the age of two to six months. They concluded, that these alterations noted at follow up suggest a possible teratogenic effect of cocaine on the development of ANS.

The majority of studies on PCE neonates focused on HRV during sleep. Within their first study, Regalado et al.report an increased inter-quartile range of the R-R intervals during quite sleep (QS) and REM in PCE neonates compared to controls (16). The authors conclude that these findings of greater HRV across both sleep states in the cocaine exposed infants may be indicative of a less finely-tuned homeostatic system allowing with greater deviations from the norm. A later study by the same group (17) reported an increase in total power during QS and active sleep (AS) in PCE compared to controls. Furthermore, MF, and LF were increased during QS, and LF was increased during AS in PCE compared to controls. The authors state, that such increases in mid and low frequency HRV are suggestive of specific effects of PCE on catecholamine sensitivity and/ or metabolism. The other study by the authors (18) supports their earlier findings. Within this study again MF, LF, and total power were increased during QS and AS in PCE neonates compared to controls. Furthermore, HF was increased during QS. The authors suggest two possibilities for the effect of cocaine exposure on the autonomic nature of HR: (1) an increase in parasympathetic control of HR in the cocaine-exposed infants; or (2) an increase in both vagal and sympathetic modulation of HR in the PCE infants. In line with their previous studies, the authors tend to favor the second possibility, since sympathovagal balance was unaffected within this study, and therefore it appears that both parasympathetic and sympathetic activities are increased. However, the study by Garde et al. (15) reports no significant differences on HRV in PCE neonates compared to controls. The authors state that they found large intersubject variability not only in the PCE group but also in the control group. Thus, they critically note, it appears that any alterations in HR dynamics in PCE neonates are likely to be too subtle for detection even by nonlinear techniques unless much larger sample sizes are employed and that this fact might contribute to explain why previous studies using spectral analysis of HRV have arrived at differing conclusions.

John et al. (14) addressed the effects of PCE on HR and HRV in the presence of orthostatic stress among near and fullterm neonates. They found decreased SDDRR in PCE neonates in the pre-tilt and intra-tilt segments compared with controls. Furthermore, PCE neonates had a different SDDRR peak. The authors conclude that the effects of PCE on the development of SNS and PNS could lead to altered cardiovascular function.

\section{Conclusion}

Cardiovascular effects of cocaine have been extensively studied by different measures of autonomic nervous system (ANS) function, such as blood pressure (BP), heart rate (HR) or likewise parameters of cardiovascular activity under different conditions. The heart rate variability (HRV) represents the continuous interplay between the sympathetic and parasympathetic branches of the ANS in regulating the $\mathrm{HR}$. Within this comprehensive review, we aimed to summarize current findings on the influence of cocaine on time- and frequency domain measures of HRV.

After extensive screening of the literature, 11 studies were included within the systematic review. Three experimental studies investigating acute effects of cocaine intake/administration in adults and eight clinical studies investigating prenatal cocaine exposure (PCE) in infants were eligible for inclusion. Surprisingly, the amount of experimental studies was relatively small and all clinical studies focused on PCE.

Evidence on the effects of acute cocaine administration on HRV from experimental studies is rare. Of the included studies within this systematic review, only three investigated HRV by an experimental design. Of these, only one intentionally aimed to investigate direct effects of cocaine administration on HRV in healthy subjects (8). The others implemented HRV as additional control variable, to investigate the effect of cocaine versus placebo on monocyte expression and potential mechanism for decreases in resting and stimulated monocyte expression of TNF- $\alpha$ and IL- 6 in cocaine dependence by assessing variations in SNS and PNS indexed by HRV (10), or to investigate whether cocaine would significantly destabilize cardiac repolarization as measured by QT variability (9). A common finding among the above studies is a decrease in high frequency (HF) of HRV after cocaine administration as reported by two studies $(8,10)$. However, the amount of experimental studies is simply too small to draw substantial conclusions based on the present evidence.

All clinical studies investigated the impact of PCE on infants right after birth, 24 to 72 hours-old, two weeks of age, or at the age of 2 to 6 months. While one study (10) report no significant effect of cocaine on HRV in PCE infants compared to controls, the majority of studies reveal significant differences. Of these, several studies report a decrease of HRV in PCE infants compared to controls (11-14), while others report an increase (16-18). The study by John et al. (14) was motivated by the presence of such conflicting results, and addressed orthostatic stress as potential source of bias. They found that PCE infants had decreased HRV in the pre-tilt and intratilt segments compared with controls, but they had similar or increased HRV in the post-tilt segment. The authors state, that moreover, the effects of cocaine exposure on ANS regulation of cardiovascular function were manifested as differences in the times to peak HRV and the duration of elevated HRV (14). The 
Koenig J et al.

authors conclude, that these increases in the presence of elevated HR (during tilt) likely reflect both sympathetic and vagal modulation in both PCE and controls, while the lower HRV measurements in PCE compared with controls (pre and intratilt), suggest the predominance of sympathetic modulation in the ANS control of cardiovascular function in PCE (14). While these findings might contribute to an integration of the aforementioned conflicting results, more research seems necessary that in particular controls for stimulus response (e.g. orthostatic stress) and condition at recording. Furthermore, more research is needed to clarify to what extent the effects of PCE persist into childhood $(12,14)$.

A general finding of the present review on the one hand is that evidence on the effects of cocaine on HRV is rare. On the other hand, existing studies encourage the use of methods of HRV measurement to study the impact of cocaine on ANS function. Besides the expansion of current fields of research (i.e. acute administration of cocaine in adults, ANS changes in cocaine dependent subjects, PCE in infants), future studies might investigate changes in HRV as potential outcome in the treatment of addictive subjects, investigate the relation of HRV differences and severity of dependency (i.e. dose-effect relation), or address likewise questions of interest.

This systematic review also revealed that in addition to the frequently used measures of HRV (Table 2) a noticeable amount of different and not so well established indices (e.g. HRVi, HRv, CorSDRR) of HRV were used within the included studies. Comparisons between different studies are therefore sometimes difficult or inappropriate. Furthermore, the interpretation of HRV measures is often unclear. For example, the LF and LF power contrary to conventional wisdom reflect the baroreflex activity rather than the sympathetic activity (19-21). We like to encourage research on the impact of cocaine on HRV, and promote a higher level of standardization, according to the measurement and interpretation of results. This said, HRV is a promising index to study changes in the ANS function within this fascinating field of research.

To conclude, evidence on the effects of cocaine on HRV is rare. Existing studies either address the impact of acute cocaine administration in adults or the effect of prenatal cocaine exposure in infants of different age groups. Current findings encourage the use of heart rate variability to index the autonomic nervous system function within this particular field of research.

\section{Acknowledgements}

We like to thank all the authors that provided us with full-text of their work. We thank the Editor-in-Chief of Archives of Neuroscience Journal for the invitation to submit our work. Furthermore, we like to thank the anonymous reviewers and editors for reviewing our manuscript.

\section{Authors'Contributions}

JK, Review the concept and design, literature search and acquisition of full-texts, drafting of the manuscript. BM, Literature search and acquisition of full-texts. TKH, Critical revision of the manuscript for important intellectual content, administrative, technical, and material support; JFT, Critical revision of the manuscript for important intellectual content, administrative, technical, and material support. MNJ, Literature search and acquisition of full-texts, drafting of the manuscript.

\section{Financial Disclosure}

There is no financial interest.

\section{Funding/Support}

This was not funded by any funding source. None of the authors were involved in any of the articles included in this systematic review.

\section{References}

1. Kloner RA, Hale S, Alker K, Rezkalla S. The effects of acute and chronic cocaine use on the heart. Circulation. 1992;85(2):407-19.

2. Nahas G, Trouve R, Manger W, Latour C. Cocaine and sympathoadrenal system. Adv Biosci. 1991;80:151-64.

3. Billman GE. Mechanisms responsible for the cardiotoxic effects of cocaine. FASEB J. 1990;4(8):2469-75.

4. Fischman MW, Schuster CR, Resnekov L, Shick JF, Krasnegor NA, Fennell W, et al. Cardiovascular and subjective effects of intravenous cocaine administration in humans. Arch Gen Psychiatry. 1976;33(8):983-9.

5. Tuncel M, Wang Z, Arbique D, Fadel PJ, Victor RG, Vongpatanasin W. Mechanism of the blood pressure--raising effect of cocaine in humans. Circulation. 2002;105(9):1054-9.

6. Moher D, Liberati A, Tetzlaff J, Altman DG, Prisma Group . Preferred reporting items for systematic reviews and meta-analyses: the PRISMA statement. BMJ. 2009;339:b2535.

7. Heart rate variability. Standards of measurement, physiological interpretation, and clinical use. Task Force of the European Society of Cardiology and the North American Society of Pacing and Electrophysiology. Eur Heart J.1996;17(3):354-81.

8. Vongpatanasin W, Taylor JA, Victor RG. Effects of cocaine on heart rate variability in healthy subjects. Am J Cardiol. 2004;93(3):385-8.

9. Haigney MC, Alam S, Tebo S, Marhefka G, Elkashef A, Kahn R, et al. Intravenous cocaine and QT variability. J Cardiovasc Electrophysiol. 2006;17(6):610-6.

10. Irwin MR, Olmos L, Wang M, Valladares EM, Motivala SJ, Fong T, et al. Cocaine dependence and acute cocaine induce decreases of monocyte proinflammatory cytokine expression across the diurnal period: autonomic mechanisms. J Pharmacol Exp Ther. 2007;320(2):507-15.

11. Mehta SK, Super DM, Salvator A, Singer L, Connuck D, Fradley LG et al. Heart rate variability in cocaine-exposed newborn infants. Am Heart J. 2001;142(5):828-32.

12. Mehta SK, Super DM, Connuck D, Kirchner HL, Salvator A, Singer $\mathrm{L}$, et al. Autonomic alterations in cocaine-exposed infants. Am Heart J. 2002;144(6):1109-15.

13. Mehta SK, Super DM, Salvator A, Fradley LG, Connuck D, Kaufman ES. Heart rate variability by triangular index in infants exposed prenatally to cocaine. Ann Noninvasive Electrocardiol. 2002;7(4):374-8.

14. John V, Dai H, Talati A, Charnigo RJ, Neuman M, Bada HS. Autonomic alterations in cocaine-exposed neonates following orthostatic stress. Pediatr Res. 2007;61(2):251-6.

15. Garde S, Regalado MG, Schechtman VL, Khoo MC. Nonlinear 
dynamics of heart rate variability in cocaine-exposed neonates during sleep. Am J Physiol Heart Circ Physiol. 2001;280(6):H2920-8.

16. Regalado MG, Schechtman VL, Del Angel AP, Bean XD. Cardiac and respiratory patterns during sleep in cocaine-exposed neonates. Early Hum Dev. 1996;44(3):187-200.

17. Regalado MG, Schechtman VL, Khoo MC, Shin J, Bean XD. Sources of heart rate variation during sleep in cocaine-exposed neonates. Ann N Y Acad Sci. 1998;846:415-8.

18. Regalado MG, Schechtman VL, Khoo MCK, Bean XD. Spectral analysis of heart rate variability and respiration during sleep in cocaine-exposed neonates. Clin Physiol. 2001;21(4):428-36.

19. Casadei B, Cochrane S, Johnston J, Conway J, Sleight P. Pitfalls in the interpretation of spectral analysis of the heart rate variability during exercise in humans. Acta Physiol Scand.
1995;153(2):125-31.

20. Moak JP, Goldstein DS, Eldadah BA, Saleem A, Holmes C, Pechnik $S$, et al. Supine low-frequency power of heart rate variability reflects baroreflex function, not cardiac sympathetic innervation. Cleve Clin J Med. 2009;76 Suppl 2:S51-9.

21. Goldstein DS, Bentho O, Park MY, Sharabi Y. Low-frequency power of heart rate variability is not a measure of cardiac sympathetic tone but may be a measure of modulation of cardiac autonomic outflows by baroreflexes. Exp Physiol. 2011;96(12):1255-61.

22. Thayer JF, Hansen AL. Noninvasive Assessment of Autonomic Influences on the Heart: Impedance Cardiography and Heart Rate Variability. In: Luecken LJ, Gallo LC editors. Handbook of physiological research methods in health psychology.. Los Angeles: Sage Publications; 2008. pp. 183-210. 